\title{
Study of Biodiesel Production from Sunflower Oil Using Non Usual Basic Polymeric Resin as Catalyst
}

\author{
Viviane Fernandes da Silva ${ }^{1,2,}{ }^{*}$, Luiz Claudio de Santa Maria ${ }^{2}$, Lenise V.F. Gonçalves ${ }^{1}$, \\ Maurício G. Fonseca ${ }^{1}$ and Luciano N. Batista ${ }^{1}$ \\ ${ }^{1}$ Instituto Nacional de Metrologia, Qualidade e Tecnologia, Laboratório de Motores e Combustíveis, Av. \\ Nossa Senhora das Graças, 50 Prédio 28, Xerém, Duque de Caxias, Rio de Janeiro, CEP 25250-020, Brazil \\ ${ }^{2}$ Universidade do Estado do Rio de Janeiro, Instituto de Química. Rua São Francisco Xavier 524, Maracanã, \\ 20550-900, Rio de Janeiro/ RJ, Brazil
}

\begin{abstract}
Biodiesel is defined as a long-chain mono alkyl (methyl, ethyl or propyl) ester of fatty acids obtained from renewable sources by transesterification reaction using an acid or base. In this work, a basic resin, Amberlyst A26, was used to produce methyl sunflower biodiesel. The iodine value, corrosion to copper, oxidative stability, specific mass, water content, acid value, cloud point and ester composition were evaluated. The heterogeneous catalyst was also characterized to verify its efficiency and its ability to be reused. We used the following analytical techniques: scanning electron microscopy (SEM), energy dispersive spectroscopy (EDS), X-rays fluorescence (XRF) and differential scanning calorimetry (DSC). The results showed that the characteristics of biodiesel made from sunflower oil using resin A26 as a catalyst are in accordance with Brazilian biodiesel regulations, except the oxidative stability. The techniques used to characterize the resin showed that it is possible to reuse the resin after regeneration.
\end{abstract}

Keywords: Biodiesel, sunflower, heterogeneous catalysis, Amberlyst, Anionic resin.

\section{INTRODUCTION}

Biodiesel has been described as the main substitute for petrodiesel. Biodiesel can be synthesized by transesterification of vegetable oils [1-3], animal fats [4], waste cooking oil [5], sludge [6] and several other feedstocks generally using a catalyst and alcohols with short carbonic chains like methanol or ethanol or branched alcohols like isopropanol.

Alkaline hydroxides (mainly $\mathrm{KOH}$ and $\mathrm{NaOH}$ ) have been used as homogeneous catalysts for transesterification with high yields [7]. Homogeneous catalysts, though effective, lead to serious contamination problems, since they are corrosive and produce by products which are difficult to separate from the reaction medium, resulting in higher production costs. The difficulties involved in the removal, handling and disposal of corrosive waste have motivated a large number of studies concerning the development and the application of heterogeneous catalyst systems [8, 9]. The use of heterogeneous catalysts makes it easier to obtain a purified product, avoiding contamination of the reaction products (mainly glycerol and esters) [10, 11]. The principal reasons for using heterogeneous catalysis in this work are that no alkaline residue is generated and there is a possibility to regenerate the catalyst.

*Address correspondence to this author at the Instituto Nacional de Metrologia, Qualidade e Tecnologia, Laboratório de Motores e Combustíveis. Av. Nossa Senhora das Graças, 50 Prédio 28, Xerém, Duque de Caxias, Rio de Janeiro, CEP 25250-020, Brazil; Tel: +55 21 21453331; Fax: +55 21 26799069;

E-mail: vsilva@inmetro.gov.br
The use of these types of catalysts would reduce the costs of purification of the reaction products. Several heterogeneous catalysts have been studied by other authors, highlighting the use of catalysts such as: $\mathrm{MgO}$ [12], sulfated zirconia [13], $\mathrm{KNO}_{3}$ and $\mathrm{KNO}_{3} / \mathrm{Al}_{2} \mathrm{O}_{3}$ [14], the anionic resins Amberlyst A-26 and A-27 [15], the cationic resin Amberlyst 15 and also zeolites ( $\mathrm{NaX}$, ETS-10, etc.) [16].

The application of ion-exchange resins as heterogeneous catalysts in different reaction systems has also been investigated in recent years [17]. Among the most employed resins are those synthesized by aqueous suspension copolymerization of styrene and divinylbenzene. Amberlyst A26 OH is a bead form, strongly basic, anionic, macroreticular, polymeric resin based on styrene crosslinked with divinylbenzene containing quaternary ammonium groups (industrial grade strongly basic polymeric resin) [18].

Amberlyst 26 is used to catalyze reactions such as aldol condensation in which a strongly basic catalyst is required. It is also used to remove anionic transition metal complexes and mercaptans from hydrocarbons. In addition, this resin is employed to remove acids from hydrocarbons and other non-polar solvents, as well as oleic acid from chlorinated hydrocarbons and to deacidify phenol-acetone solutions. Its porous structure makes it a good polymeric catalyst in non-aqueous and aqueous media and it has no $\mathrm{pH}$ limitations, besides having high resistance to organic fouling [19]. Since fresh resin presents fluorine ions as counter ions, some 
ions can interact with lipids and take part in the oxidation reaction. The hypothesis that ionic species can affect the stability of lipids is supported by the fact that chaotropic ions are able to destabilize the lipid bilayer structure of cell membranes by reducing the energy required to expose the non-polar groups within the membrane to the environment $[20,21]$. The opposite effect is expected for antichaotropic ions. Therefore, one may speculate that ions can interact with lipids undergoing oxidation. Since hydroperoxides are more polar than the lipids from which they originate [22], ionic species may change hydroperoxides' conformation, modifying their oxidation kinetics.

In this work, the anionic resin Amberlyst A26 OH was utilized to produce methyl biodiesel from sunflower oil by transesterification, and some parameters related to biodiesel quality, such as ester content, iodine number, copper strip corrosion, density, water content, cloud point and oxidative stability were measured. Sunflower oil was chosen for biodiesel production because there is a government program to introduce this crop as an alternative to tobacco [23] in some regions of Brazil.

\section{EXPERIMENTAL SECTIONS}

The resin Amberlyst A-26 from Rohm and Haas was previously activated with a sodium hydroxide solution (2 M) for $24 \mathrm{~h}$ at $50{ }^{\circ} \mathrm{C}$, and then the resin was washed and dried. After this process, the resin was swollen with methanol (GC grade from Tedia) during $24 \mathrm{~h}$ at $50 \stackrel{\circ}{\circ}$. The resin's physical properties are presented in Table 1. Catalyst regeneration was done using a similar proceedings of activation but with a previously washing and drying step.

Biodiesel was obtained by heterogeneous catalysis using alkaline transesterification. Amberlyst $\mathrm{A} 26 \mathrm{OH}$ was employed as catalyst in methanol following these parameters: molar ratio of oil / methanol: $1 / 150$ and percentage of catalyst for the mass of oil: $12.5 \%$. The reaction occurred for $8 \mathrm{~h}$ at $50^{\circ} \mathrm{C}$.

Previously works, not published, with low proportion of alcohol show no activity to catalyst this reaction.
After the reaction, the catalyst was filtered with the aid of a funnel. The mixture was transferred to a separating funnel and settled for $24 \mathrm{~h}$. This procedure was necessary to enhance separation and consequently increase the yield. After the separation step, the upper phase contained methanol and biodiesel and the lower one glycerin. The upper phase was evaporated for alcohol recovery. The biodiesel obtained was washed with water until achieving neutral $\mathrm{pH}$. To remove traces of contaminants, the biodiesel was maintained at $50{ }^{\circ} \mathrm{C}$ for $24 \mathrm{~h}$.

To obtain biodiesel through homogeneous catalysis, we used the method described by Geris [24]. The parameters used for the transesterification reaction were: molar ratio of oil / methanol / catalyst: 1 / 7 / 0.3 . The products were obtained after $30 \mathrm{~min}$ at $45^{\circ} \mathrm{C}$.

To avoid soap formation acid value and water content was controlled down of $0.26 \mathrm{mg} \mathrm{KOH} / \mathrm{g}$ and $450 \mathrm{mg} / \mathrm{kg}$ respectively.

\section{Physical and Chemical Characterization of Biodiesel from Sunflower Oil}

The esters and linolenic acid concentrations were determined by gas chromatography (GC) with a flame ionization detector (FID) (EN 14103:2007), using an Agilent/AC "all in one" device. The ester composition was also determined by CG/FID in an Agilent model 6890 device with a CP-Wax 52CB capillary column (30 $\mathrm{m} \times 0.32 \mathrm{~mm} \times 0.25 \mathrm{um}$ ), with the following parameters: oven temperature of $250^{\circ} \mathrm{C}$; detector temperature of $250{ }^{\circ} \mathrm{C}$; injector temperature of $250 \stackrel{\circ}{\circ}$; split of $100: 1$; He as carrier gas; and column pressure of 12.94 psi.

The switch to copper corrosion was determined according to ASTM D-130, and the iodine value was determined according to EN 14111. The acid Value was determined by the method described in ASTM D664. The oxidative stability according to EN 14112 (cloud point) was measured according to ASTM -2500. Specific gravity was determined according to ASTM D4052 using a Mettler Toledo DE 51 digital hydrometer. The methodology for the analysis of the water content in oil and biodiesel was developed by the Organic Analysis Laboratory of INMETRO. Coulometric Karl

Table 1: Physical Properties of Amberlyst A26 OH

\begin{tabular}{|c|c|c|c|c|}
\hline Physical form & Surface area $\left(\mathbf{m}^{2} / \mathbf{g}\right)$ & Average pore diameter $(\mathbf{A})$ & Temperature limit $\left({ }^{\circ} \mathbf{C}\right)$ & Particle size $(\mathbf{m m})$ \\
\hline \hline Spherical beads & 30 & 290 & 60 & $0.560-0.700$ \\
\hline
\end{tabular}

Source: Rohm and Haas, 2003. 
Fischer titration with an oven coupled to an auto sampler was utilized [25].

Differential scanning calorimetry analyses were performed with a DSC Q2000 from TA Instruments, with RCS cooling accessory, under the following conditions: sample mass of $1-3 \mathrm{mg}$; nitrogen atmosphere (flow of $50 \mathrm{~mL} / \mathrm{min}$ ); temperature ranges from 20 to $-90{ }^{\circ} \mathrm{C}$ and -90 to $20{ }^{\circ} \mathrm{C}$; and cooling and heating ratio of $0.5^{\circ} \mathrm{C} / \mathrm{min}$.

\section{Determination of Polymer Resin Properties}

Scanning electron microscopy (SEM) analyses were performed in a Quanta 200 scanning electron microscope. The samples were placed in aluminum holders and carbon ribbon. The images were obtained using the SEM in low-vacuum operating condition $(0.45$ Torr) with accelerating voltage of $20 \mathrm{kV}$ and increased $100 \mathrm{x}$ and 300x. To determine the elemental composition by EDS, an accelerating voltage of $15 \mathrm{kV}$ and 200x magnification were used.

X-rays fluorescence tests were carried out using a Bruker S4 Pioneer model X-ray fluorescence device with a rhodium target tube operating at $27 \mathrm{kV} \times 148$ $m A$. A crystal analyzer was used for the EGG-C line of nitrogen. The crystal used covers both the range of energy for nitrogen and for carbon and oxygen. The samples were pressed at 10 tonnes for about $1 \mathrm{~min}$. The pellets were placed separately in the specimen holder of the apparatus to perform the X-ray fluorescence tests. The trials took place inside a vacuum chamber.

\section{RESULTS AND DISCUSSION}

The molar ratio used for the biodiesel transesterification reaction carried out by homogeneous catalysis was satisfactory, because the total content of esters obtained was $99.1 \%$, above the minimum specified by ANP Resolution 7, which is $96.5 \%$. The reaction yield of biodiesel expressed in mass / mass of oil was $85 \%$.

The biodiesel reaction yield, using heterogeneous catalyst expressed as mass / mass of oil was $40 \%$ using molar ratio (methanol/oil) 150:1 and total esters content was $87.5 \%$, below the minimum specified by the Brazilian resolution. Lower molar ratio of methanol was applied too but no relevant yield and activity were detected. Although high molar ratio of methanol its possible recovers solvent and we will be use amberlyst A-26 into continuous tubular reactor with large amount of methanol. Lower contents of catalyst (1,3 and $6 \%$ ) presents low yield about $30 \%$.

Amberlyst A26 OH under cited was regeneratated four times with reduction of yield about $5 \%$, after resin yield decays about $10 \%$ by regeneration.

Table 2 shows the quantification results of methyl biodiesel fatty acid esters by heterogeneous and homogeneous catalyses.

\section{Physical-Chemical Characterization of Biodiesel from Sunflower Oil}

The physical-chemical characterization of biodiesel made from sunflower oil was accomplished through analysis of the oxidative stability, corrosion to copper, point cloud, density, water content (using Karl Fischer coulometric), iodine value, acid value and flash point. The characterization results are shown in Table 3.

With regard to oxidation stability, both biodiesel from the homogeneous catalysis and from the heterogeneous process presented induction times below the limit established by the ANP. Due to the predominance of unsaturated fatty acids, sunflower biodiesel is less stable in the process of oxidative degradation than other biodiesel types that mainly

Table 2: Esters Composition (\%) of Sunflower Biodiesel in Parenthesis Corrected Values (Discounted Impurities)

\begin{tabular}{|c|c|c|}
\hline Methyl Esters & Methylic Biodiesel (KOH) (g/100g) & Methylic Biodiesel (A26OH) (g/100g) \\
\hline \hline Palmitic (C16:0) & $6.56(6.62)$ & $4.75(5.43)$ \\
\hline Stearic (C18:0) & $4.65(4.69)$ & $7.08(8.09)$ \\
\hline$\sum$ saturates & $11.21(11.31)$ & $13.13(15.01)$ \\
\hline Oleic (C18:1) & $22.12(22.32)$ & $67.24(76.89)$ \\
\hline Linoleic (C18:2) & $65.77(66.37)$ & $80.37(91.90)$ \\
\hline$\sum$ unsaturated & $87.89(88.69)$ & $87.45(100.00)$ \\
\hline$\sum$ total esters & $99.10(100.00)$ & \\
\hline
\end{tabular}


Table 3: Biodiesel Physical Chemistry Parameters

\begin{tabular}{|c|c|c|c|}
\hline Parameters & Biodiesel methyl (KOH) & $\begin{array}{c}\text { Biodiesel methyl } \\
\text { (A26OH) }\end{array}$ & $\begin{array}{c}\text { Brazilian regulamentation } \\
\text { (ANP 7) }\end{array}$ \\
\hline Oxidative stability $^{\mathrm{a}}(\mathrm{h})$ & 0.36 & 0.54 & 6 \\
\hline Copper corrosion & 1 & 1 & 1 \\
\hline Cloud point $\left({ }^{\circ} \mathrm{C}\right)$ & 1.5 & - & - \\
\hline Specific gravity $\left(\mathrm{kg} / \mathrm{m}^{3}\right)$ & 883 & 876 & 850 to 900 \\
\hline Water content ${ }^{\mathrm{b}}(\mathrm{mg} / \mathrm{kg})$ & 450 & 360 & 500 \\
\hline lodine value $\left(\mathrm{g} \mathrm{I}_{2} / 100 \mathrm{~g}\right)$ & 117.272 & 123.654 & Take note \\
\hline
\end{tabular}

${ }^{a}$ minimum; ${ }^{b}$ maximum.

contain esters from saturated fatty acids. The absence of double bonds in the acyl group chain (R-CO-) reduces the possibility of oxygen attack in these sites. These saturated fatty acids improve the stability of the oxidation process. The biodiesel derived from other plant oils has higher oxidative stability, in general behaving differently than biodiesel from sunflower oil.

It is noteworthy, however, that these biodiesels mainly containing esters from saturated fatty acids do not need addition of any type of antioxidant. The induction time can be increased with the use of both natural and synthetic antioxidants. This parameter is critical for storage and transportation of biodiesel.

The water content of the sunflower biodiesel was in accordance with Brazilian specifications.

The cloud point is related to the beginning of the crystallization process. The results indicate that none of the samples has a risk of crystallization risk/solidification under typical Brazilian climate conditions. While the cloud point is not specified in Brazilian regulations, it can be an important factor in the southern regions of Brazil during the winter, where temperatures occasionally fall to freezing.

The corrosion to copper and acid value is both related to the corrosion phenomena and biodiesel with high values of these parameters can cause deposits in injection systems. Both these values were analyzed in light of the specified limits, indicating a low risk of corrosion of the material produced. The density results at $20{ }^{\circ} \mathrm{C}$ indicated that the biodiesel produced in this study met the specification limits for this parameter.

The data obtained in this work show that the two types of sunflower biodiesel produced from unrefined oils are within most of the specified parameters.

\section{Differential Scanning Calorimetry (DSC)}

Figures 1 and 2 show differential scanning calorimetry curves of methyl biodiesel processed via

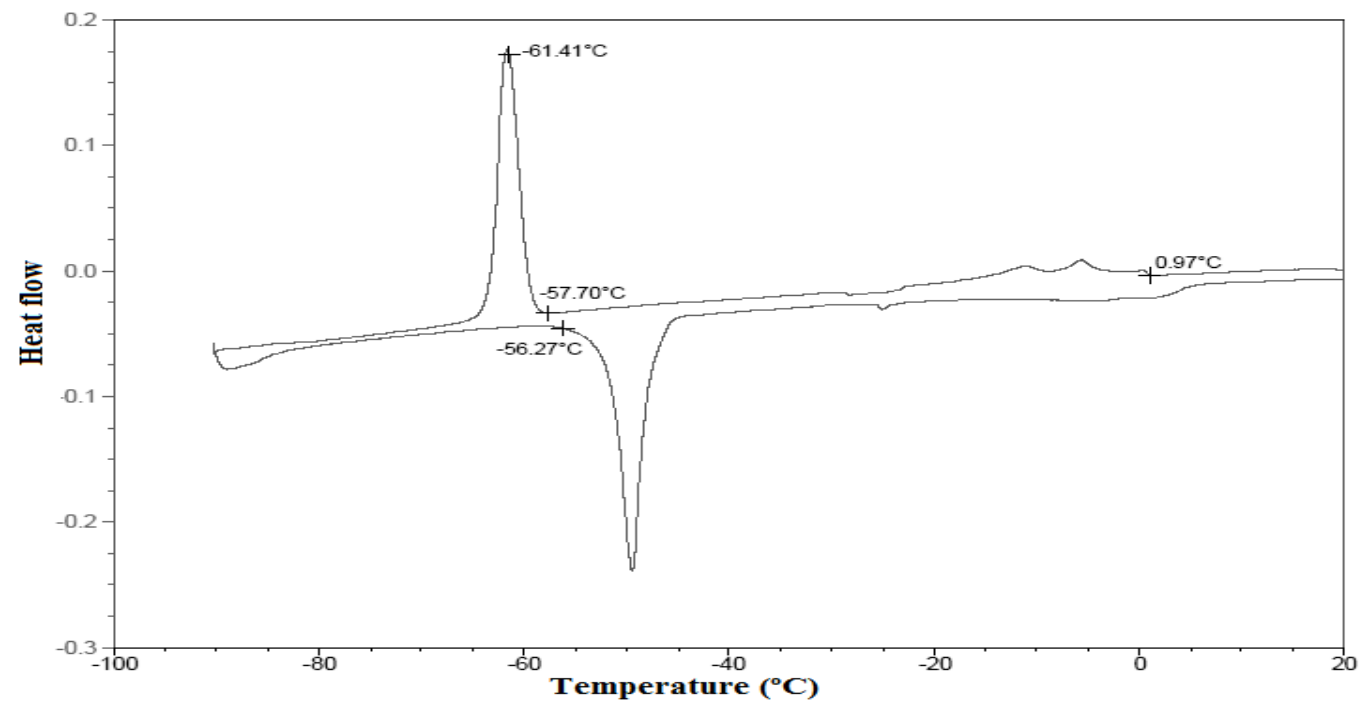

Figure 1: Differential scanning calorimetry of methyl sunflower biodiesel with $\mathrm{KOH}$ as catalyst. 


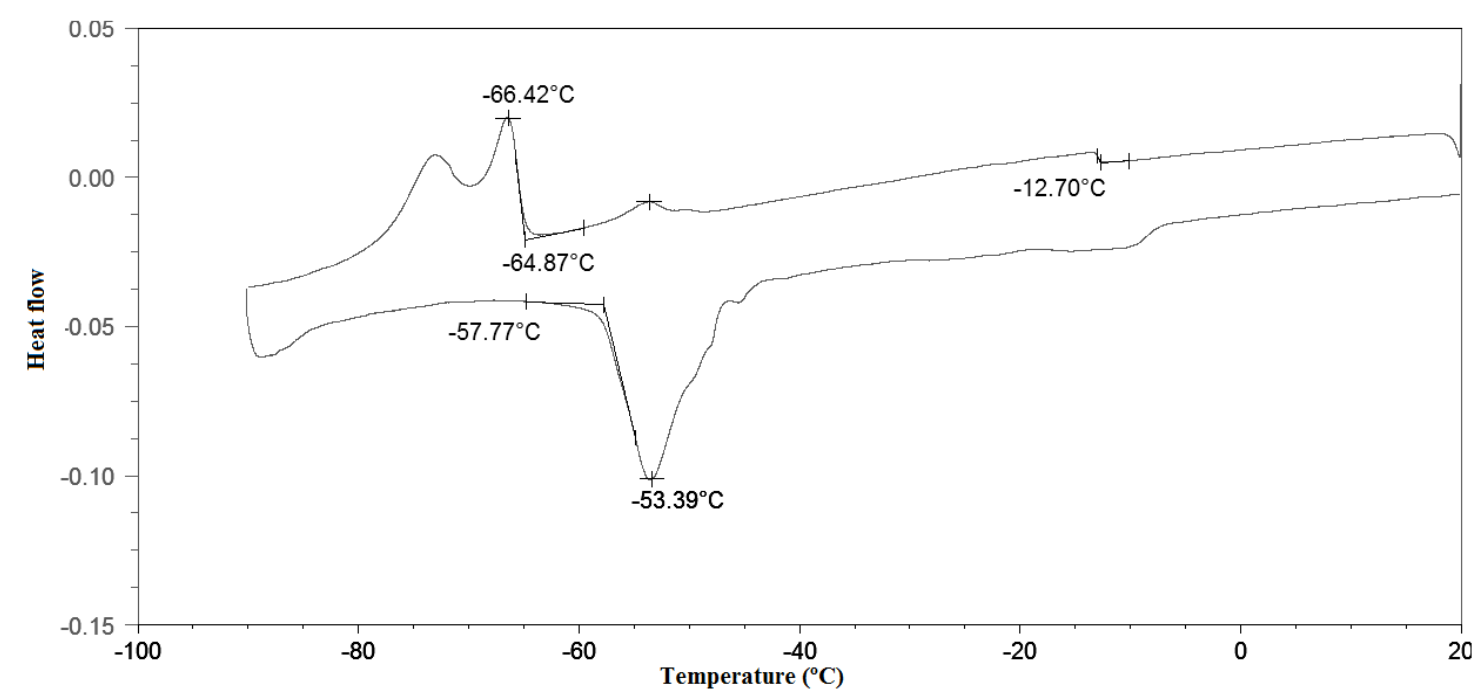

Figure 2: Differential scanning calorimetry of methyl sunflower biodiesel obtained with $\mathrm{A} 26 \mathrm{OH}$ resin as catalyst.

homogeneous and heterogeneous catalyses. The top line is the cooling curve of the sample while the lower one is the heating curve.

Exothermic events are represented by the endothermic peaks, observed as depressions. The first event (onset) of the methyl sunflower biodiesel (Figure 1) occurred at $0.97{ }^{\circ} \mathrm{C}$, indicating probable crystallization of saturated methyl esters such as methyl palmitate and methyl stearate, whose melting points are respectively 63 and $70{ }^{\circ} \mathrm{C}$.

As the concentration of these esters is usually low in sunflower oil, the exothermic peak is small. The onset temperature should indicate the start of the event, in this case the onset of crystallization of saturated esters. This same phenomenon should also be detected by the cloud point. The temperature found for the cloud point was $1.5^{\circ} \mathrm{C}$. This difference between the two techniques is within the measurement error of the equipment. Symmetrical peaks about $-60^{\circ} \mathrm{C}$ due of methyl oleate and methyl linoleate crystalization.

Figure 2 shows the crystallization curve of the methyl biodiesel synthesized with $\mathrm{A} 26$ resin as a catalyst. The initial temperature is $-12{ }^{\circ} \mathrm{C}$, indicating the probable crystallization of saturated methyl esters.

Peaks of oleic methyl ester and linoleic methyl ester presents a unsymmetrical behavior and lower crystallization temperature, its probably are caused by presence of contamination as glycerol monooleate or fluorine session (see XPS analysis). These contaminants impact a fatty acid methyl ester crystal nucleus formation modifying standard behavior.

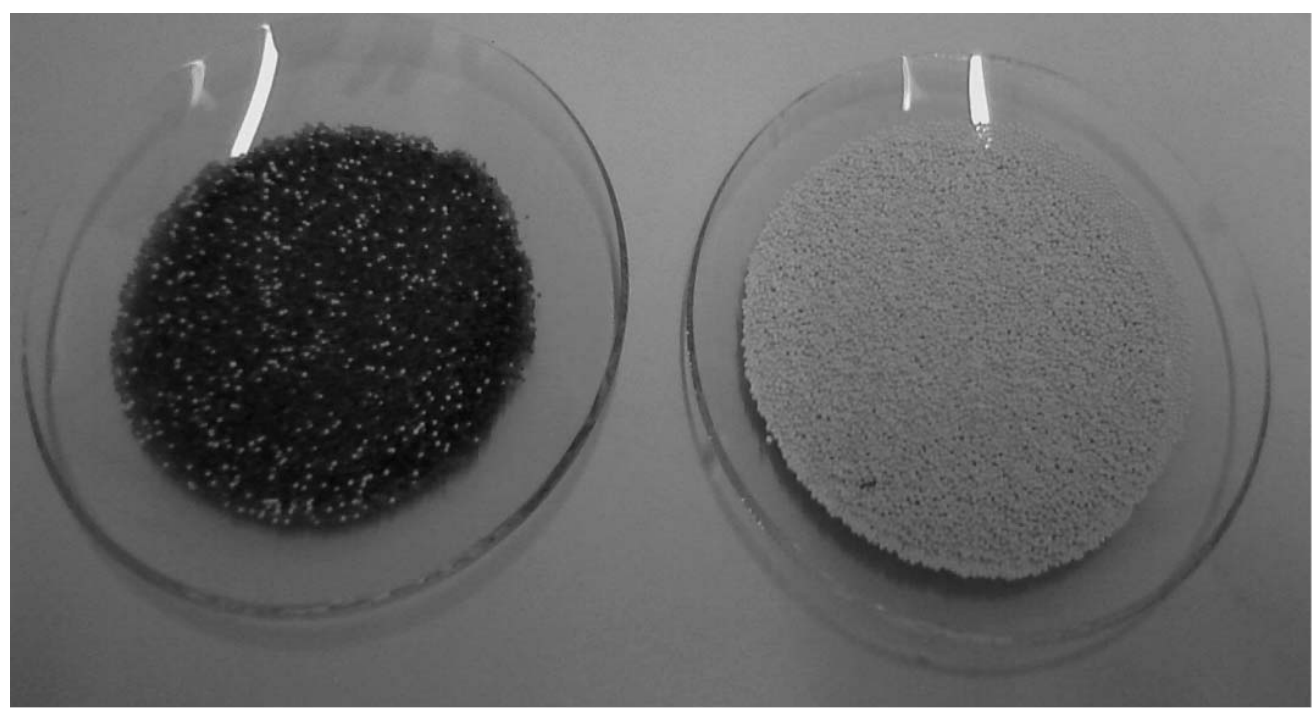

Figure 3: New resin (left) and regenerated resin (right) - Scanning electron microscopy (SEM). 

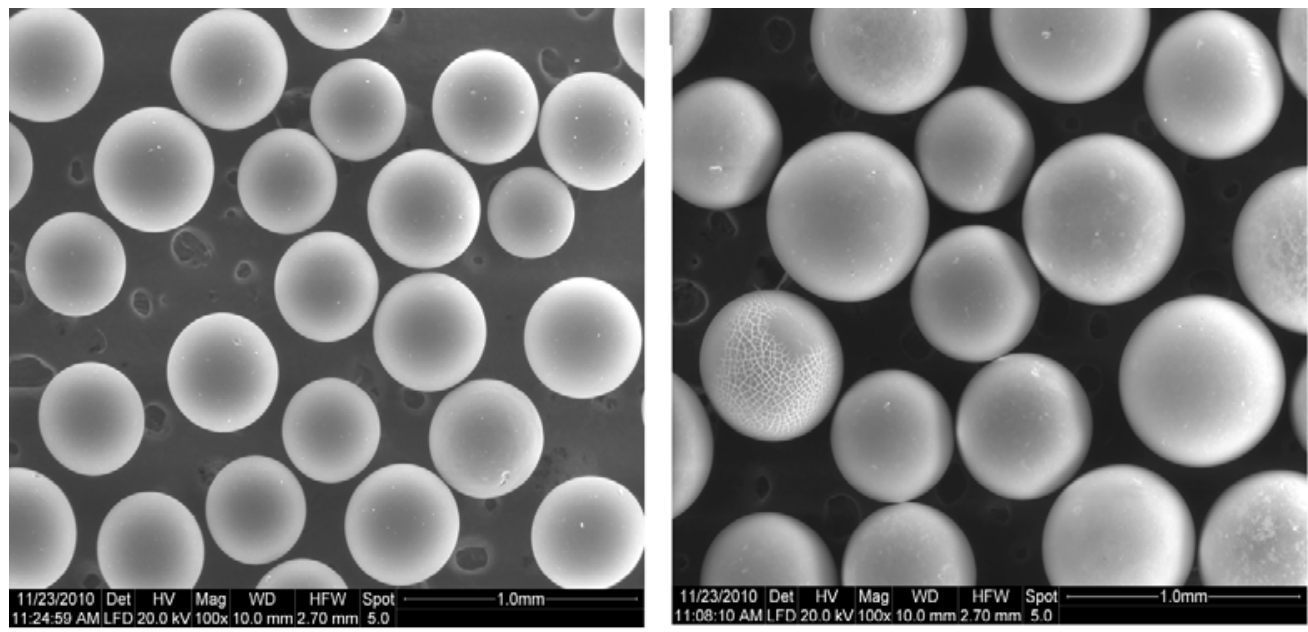

Figure 4: Scanning electron micrographs with increase of $100 \mathrm{x}$ - new resin (left) and regenerated resin (right).

\section{Determination of Polymer Resin Properties}

Analyses were performed on the new $\mathrm{A} 26 \mathrm{OH}$ resin and on the regenerated resin to check for changes in its structure when reused. Figure 3 shows images of new and regenerated resin. It is possible to see a change in its color and size. This is due to the treatment performed on the regenerated resin. The regenerated resin shows swelling, unlike the new resin without treatment.

Figures 4 and $\mathbf{5}$ are micrographs at two different magnifications of the new resin and regenerated resin. In both cases the resins have spherical structure. The new resin has an average diameter smaller than the regenerated resin. There was variation between 350 and 570 microns in the case of resin regeneration between 500 and $720 \mathrm{mM}$. The variation in diameter of the particles was determined on the basis of SEM

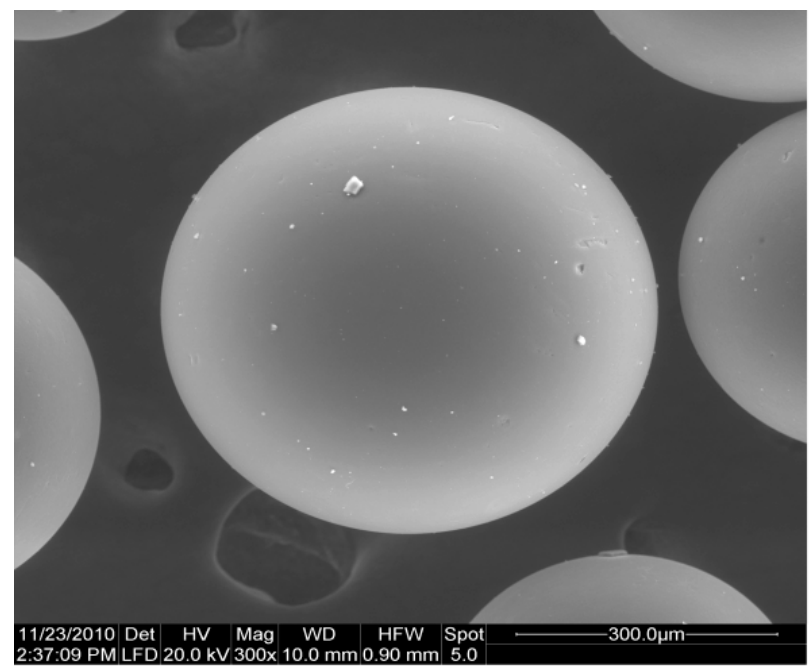

images with $100 \times$ magnification. These values are within those specified by the manufacturer, so the use of $\mathrm{A} 26 \mathrm{OH}$ in the synthesis of biodiesel does not cause a change in the resin's shape or size.

Although no changes occurred beyond the manufacturer's specifications, some regenerated resin particles had small cracks, which might have been caused by mechanical impact of the magnetic stirrer or by breaking or separation of the polymer chains. This fact indicates that this resin can become degraded after successive regenerations.

\section{Energy Dispersive Spectroscopy (EDS)}

The analysis by energy dispersive spectroscopy of the new resin (Figure 6) and regenerated resin (Figure 7) showed the presence of $C$ and $O$, which is consistent with a functionalized poly(styrenedivinylbenzene) resin.

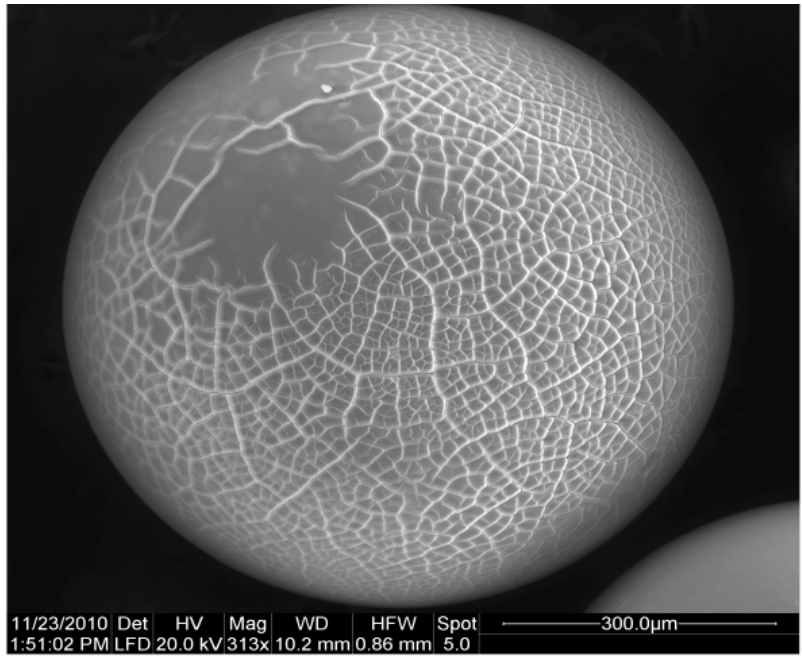

Figure 5: Scanning electron micrographs with increased of $300 \mathrm{x}$ - new resin (left) and regenerated resin (right). 


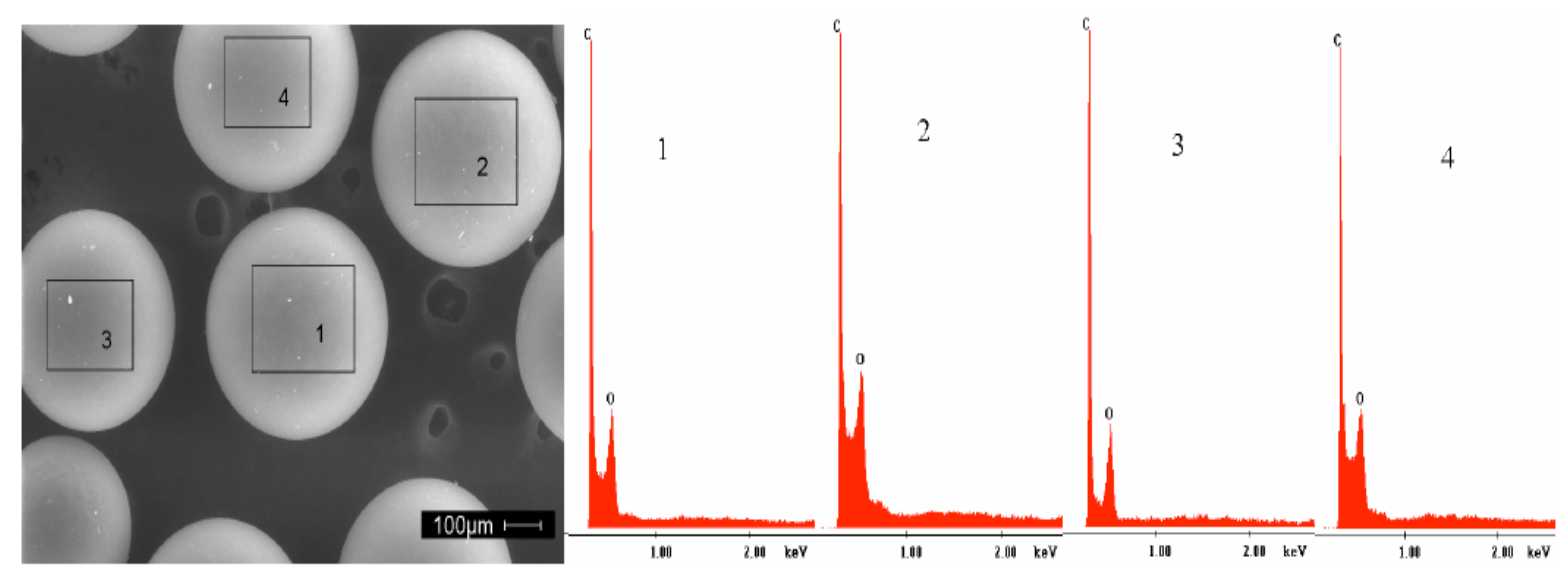

Figure 6: EDS of the new resin.
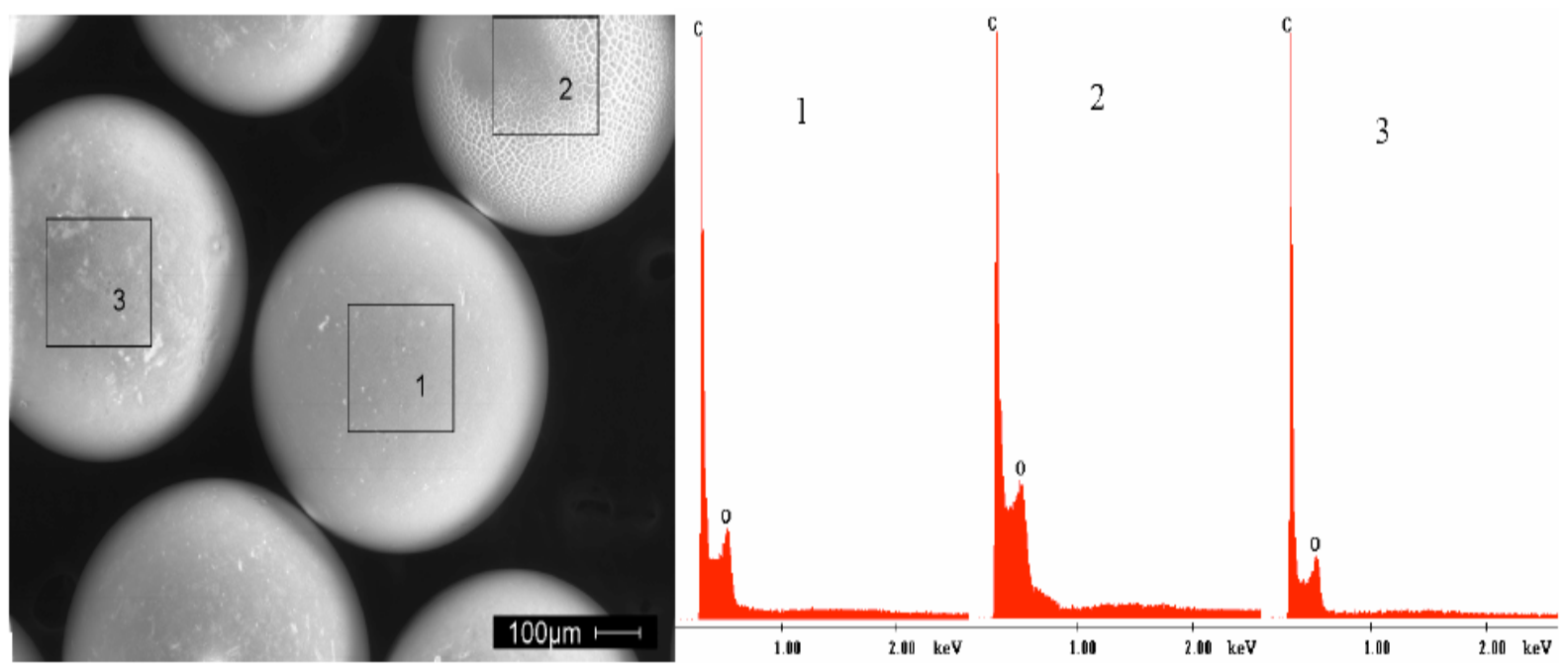

Figure 7: EDS of the regenerated resin.

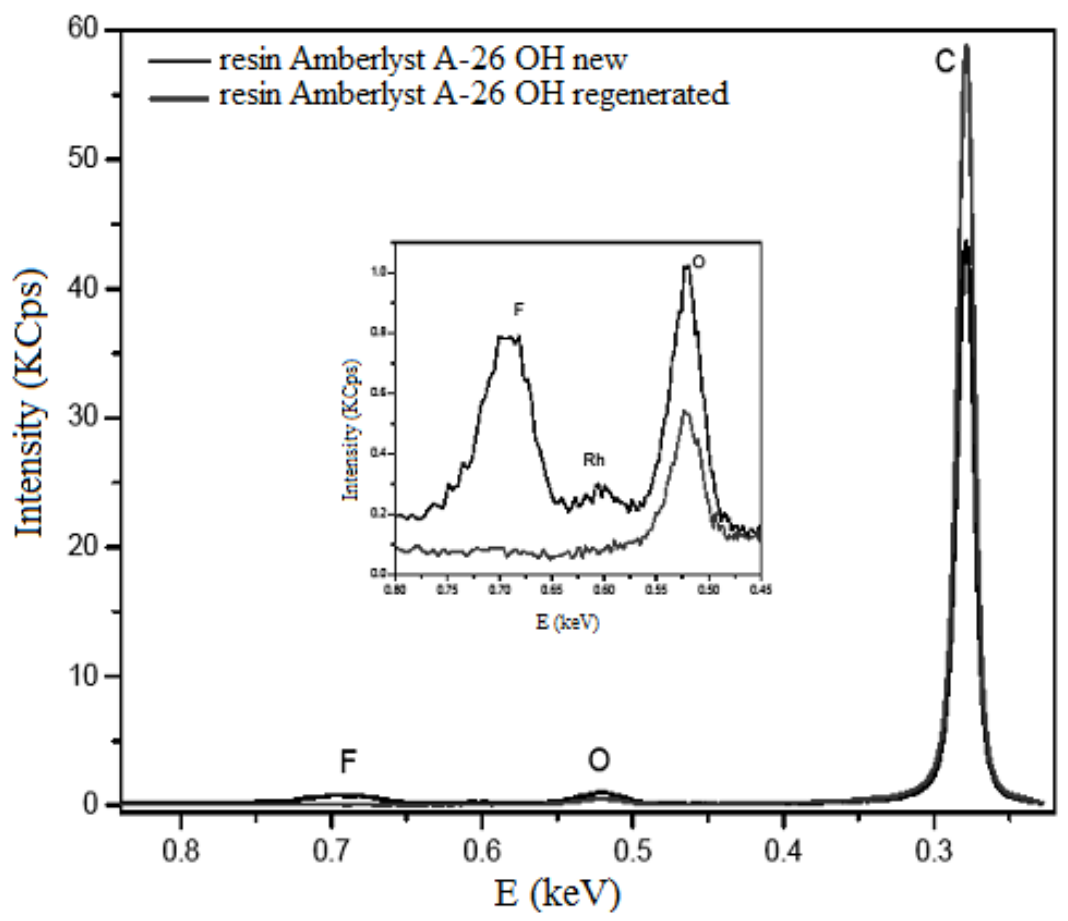

Figure 8: X-ray fluorescence (XRF) of new and regenerated resin. 


\section{X-Ray Fluorescence (XRF)}

The analysis by X-rays fluorescence of the new and regenerated resin (Figure 8 ) showed the presence of $C$ and $\mathrm{O}$, which is in agreement with the EDS analysis. The tests were unable to detect nitrogen, probably due to the use of a vacuum as required by the techniques.

Fluoride was identified in the new resin, in contrast to the regenerated resin, where it was not detected. Fluoride ions are typically present in the initial resin, so their detection is not unusual in analysis of resin carried out before the activation process ( $\mathrm{NaOH}$ treatment) $\mathrm{Rh}$ peaks always appear in fluorescence analysis because this atom is found in the source.

\section{CONCLUSION}

Amberlyst A26 resin can promote a transesterification reaction, but present low yield and it is necessary to use a high proportion of alcohol (150:1) and longer reaction time mainly compared with homogeneous catalyst( yield about 95\%). Now, our group have been development a tubular reaction The ester composition was influenced by the catalyst, generating a different biodiesel composition. This property can be used to improve biodiesel's physicalchemistry properties. This resin can be regenerated with some degradation, but there is no large-scale physical degradation. New basic resins should be prepared to use this synthesis, but it is necessary to improve the yield and reduce the reaction time.

\section{ACKNOWLEDGEMENTS}

We thank Gabriela Moreira for the DSC analysis; Taeko Fukuhara for the MEV and EDX analyses; and Érica Cravina for the XRF analysis. We also thank Rohm and Haas for donating the resin used in this work.

\section{REFERENCES}

[1] Meher LC, Vidya SD, Naik SN. Technical aspects of biodiesel production by transesterification-a review. Renew Sust Energ Rev 2006; 10: 248-68.

http://dx.doi.org/10.1016/j.rser.2004.09.002

[2] Alberici RM, Simas RC, Abdelnur PV, Eberlin MN, Souza V, Sá GF, Daroda RJ. A Highly Effective Antioxidant and Artificial Marker for Biodiesel. Energy Fuels 2010; 24: 652226.

\section{http://dx.doi.org/10.1021/ef100968b}

[3] Abbazaadeh A, Ghobadian B, Omidkhah MR, Najafi G. Current biodiesel production technologies: A comparative review. Energ Convers Manage 2012; 63: 138-48. http://dx.doi.org/10.1016/j.enconman.2012.02.027
Andersen $\mathrm{O}$, Weinbach J. Residual animal fat and fish for biodiesel production. Potentials in Norway. Biomass Bioenergy 2010; 34: 1183-88.

http://dx.doi.org/10.1016/j.biombioe.2010.03.010

[5] Canakci M. The potential of restaurant waste lipids as biodiesel feedstocks. Bioresour Technol 2007; 98: 183-90. http://dx.doi.org/10.1016/j.biortech.2005.11.022

[6] Kargbo DM. Biodiesel Production from Municipal Sewage Sludges. Energy Fuels 2010; 24: 2791-94. http://dx.doi.org/10.1021/ef1001106

[7] Hoissain ABMS, Boyce AN. Biodiesel production from waste sunflower cooking oil as an environmental recycling process and renewable energy. Bulg J Agric Science 2009; 15: 31217.

[8] Lotero E, Liu Y, Lopez DE, Suwannakarn K, Bruce DA, Goodwin Jr. JC. Synthesis of Biodiesel via Acid Catalysis. Ind Eng Chem Res 2005; 44: 5353-63. http://dx.doi.org/10.1021/ie049157g

[9] Pinto AC, Guariero LLN, Rezende MJC. Biodiesel: an overview. J Braz Chem Soc 2005; 16: 1313-30. http://dx.doi.org/10.1590/S0103-50532005000800003

[10] Ramachandran K, Suganya T, Nagendra GN, Renganathan S. Recent developments for biodiesel production by ultrasonic assist transesterification using different heterogeneous catalyst: A review. Renewable Sustainable Energy Rev 2013; 22: 410-18. http://dx.doi.org/10.1016/j.rser.2013.01.057

[11] Atadashi IM, Aroua MK, Abdul AR, Sulaiman NMN. The effects of catalysts in biodiesel production: A review. J Ind Eng Chem 2013; 19: 14-26.

http://dx.doi.org/10.1016/j.jiec.2012.07.009

[12] Di Serio M, Cozzolino LM, Minutillo G, Tesser R, Santacesaria E, Transesterification of Soybean Oil to Biodiesel by Using Heterogeneous Basic Catalysts. Ind Eng Chem Res 2006; 45: 3009-14.

http://dx.doi.org/10.1021/ie0514020

[13] Kiss AA, Dimian AC, Rothenberg G. Solid Acid Catalysts for Biodiesel Production --Towards Sustainable Energy. Adv Synth Catal 2006; 348: 75-81. http://dx.doi.org/10.1002/adsc.200505160

[14] Xie W, Peng H, Chen L. Transesterification of soybean oil catalyzed by potassium loaded on alumina as a solid-base catalyst. Appl Catal A 2006; 300: 67-74. http://dx.doi.org/10.1016/j.apcata.2005.10.048

[15] Vicente G, Coteron A, Martinez M, Aracil J. Application of the factorial design of experiments and response surface methodology to optimize biodiesel production. Ind Crops Prod 1998; 8: 29-35. http://dx.doi.org/10.1016/S0926-6690(97)10003-6

[16] Suppes GJ, Dasar MA, Doskocil EJ, Mankidy PJ, Goff MJ. Transesterification of soybean oil with zeolite and metal catalysts. Appl Catal A 2004; 257: 213-23.

http://dx.doi.org/10.1016/j.apcata.2003.07.010

[17] Awad S, Paraschiv M, Varuvel EG, Tazerout M. Optimization of biodiesel production from animal fat residue in wastewater using response surface methodology. Bior Techn 2013; 129: 315-20. http://dx.doi.org/10.1016/j.biortech.2012.11.086

[18] Rohm and Haas Company 2003, PDS 0322 A http://www.amberlyst.com [accessed on Sept 2009).

[19] Ilgen O, Akin AN, Boz N. Investigation of Biodiesel Production from Canola Oil Using Amberlyst-26 as a Catalyst. Turk J Chem 2009; 33: 289-94.

[20] Cacace MG, Landau EM, Ramsden JJ. The Hofmeister series: salt and solvent effects on interfacial phenomena. $Q$ Rev Biophys 1997; 30: 241-77. http://dx.doi.org/10.1017/S0033583597003363 
[21] Calligaris S, Nicoli MC. Effect of selected ions from lyotropic series on lipid oxidation rate. Food Chem 2004; 94: 130-34. http://dx.doi.org/10.1016/j.foodchem.2004.11.002

[22] Nuchi CD, Hernadez P, McClements DJ, Decker EA. Ability of Lipid Hydroperoxides To Partition into Surfactant Micelles and Alter Lipid Oxidation Rates in Emulsions. J Agric Food Chem 2002; 50: 5445-49.

http://dx.doi.org/10.1021/jf020095j

[23] Porte AF, Schneider RCS, Kaercher JA, Klamt RA, Schmatz WL, Silva WLT, Severo Filho WA. Sunflower biodiesel production and application in family farms in Brazil. Fuel 2010; 89: 3718-24.

http://dx.doi.org/10.1016/.juel.2010.07.025

[24] Geris R, Santos NAC, Amaral BA, Maia IS, Castro VD, Carvalho JRM. Biodiesel from soybean oil - experimental procedure of transesterification for organic chemistry laboratories. Quim Nova 2007; 30: 1369-73.

http://dx.doi.org/10.1590/S0100-40422007000500053

[25] Vicentim MP, Sousa MVB, Silva VF, Mateus VL, Rodrigues JM, Smarçaro V. C J ASTM Int 2009; 7: 1-7. 